\title{
A novel mutation in PCCB gene causing neonatal onset propionic acidaemia in a Sri Lankan patient
}

*Niranjalee Samanthika Egodawaththe ${ }^{1}$, Sandya Bandara ${ }^{1}$, Eresha Jasinge ${ }^{2}$, Patricia Jones $^{3}$

Sri Lanka Journal of Child Health, 2021; 50(1): 153-155

DOI: http://dx.doi.org/10.4038/sljch.v50i1.9418

(Key words: Propionic acidaemia, hyperammonaemia, ketotic hyperglycinaemia, neonatal encephalopathy)

\section{Introduction}

Propionic acidaemia (PA) is a severe intoxication type organic acidaemia and is characterized by the accumulation of propionic acid due to the deficiency of propionyl-CoA carboxylase (PCC) ${ }^{1}$. In 1961, Childs et al initially described a new metabolic disorder and named it "ketotic hyperglycinaemia" which later enzymatically turned out to be PA and methyl malonic acidaemia $^{2}$. We report a classic case of PA, highlighting the importance of metabolic screening in cases of neonatal encephalopathy of unknown aetiology.

\section{Case report}

A 16-day-old baby boy, the third born of healthy consanguineous parents, presented to the routine well-baby clinic with a two-day history of vomiting, refusal to feed and lethargy. There was a $14 \%$ weight loss from birth. The baby was exclusively breastfed. He was a term, appropriate for gestational age baby. The pregnancy and delivery were uncomplicated. There was a death of a male sibling at the age of 14 days, where the symptomatology resembled this peculiar presentation. That death was attributed to fungal septicaemia. The elder child was a 5-year-old healthy girl.

Examination revealed a moderately dehydrated neonate with stable vital signs. Baby deteriorated gradually over the next few days and evolved into encephalopathy. There were no seizures or organomegaly. Subsequently, he became apnoeic and went into respiratory failure, requiring ventilatory support.

Initial investigations revealed leucopenia with neutropenia and marked thrombocytopenia (Table 1).

Table 1: White cell and platelet counts, arterial blood gases and serum electrolytes

\begin{tabular}{|l|c|c|c|}
\hline \multicolumn{1}{|c|}{ Investigation } & Reference range & On admission & Day 3 \\
\hline White cell count $\left(\times 10^{3} / \mu \mathrm{L}\right)$ & $6-21$ & 4.1 & 3.9 \\
\hline Neutrophil count $\left(\times 10^{3} / \mu \mathrm{L}\right)$ & $1.5-5.4$ & 1.3 & 0.45 \\
\hline Platelet count $\left(\times 10^{3} / \mu \mathrm{L}\right)$ & $150-400$ & 101 & 87 \\
\hline $\mathrm{pH}$ & $7.35-7.45$ & 7.46 & 11.5 \\
\hline Bicarbonate $(\mathrm{mmol} / \mathrm{L})$ & $21-28$ & 26 & -20 \\
\hline Base excess $(\mathrm{mmol} / \mathrm{L})$ & -10 to -2 & -2 & 141 \\
\hline Serum sodium $(\mathrm{mmol} / \mathrm{L})$ & $133-146$ & 138 & 4.1 \\
\hline Serum potassium $(\mathrm{mmol} / \mathrm{L})$ & $3.4-6.0$ & 4.3 & 111 \\
\hline Serum chloride $(\mathrm{mmol} / \mathrm{L})$ & $98-106$ & & 18.5 \\
\hline Anion gap $(\mathrm{mmol} / \mathrm{L})$ & $8-16$ & & \\
\hline
\end{tabular}

\section{${ }^{1}$ Teaching Hospital Peradeniya, Sri Lanka, ${ }^{2}$ Lady Ridgeway Hospital for Children, Colombo, Sri Lanka, ${ }^{3}$ Chemistry and Metabolic Disease Laboratory Medical Centre, Dallas, Texas, USA *Correspondence: samanthika41@gmail.com}

https://orcid.org/0000-0002-8137-0737 (Keceived on 14 February 2020: Accepted after revision on 17 April 2020)

The authors declare that there are no conflicts of interest

Personal funding was used for the project.

Open Access Article published under the Creative

Commons Attribution CC-BY (c) (i) License
Basic renal and liver functions, blood glucose, serum electrolytes, clotting profile and C-reactive protein were within normal limits. The initial arterial blood gases showed normal values, but during the latter course of the illness, there was marked metabolic acidosis (MA) (Table 1).

Urinalysis revealed ketonuria. Imaging studies revealed a normal ultrasound scan of the brain and abdomen. Roentgenogram of the chest was normal.

Late-onset sepsis was the initial differential diagnosis. However, the previous death of a male sibling and evolving encephalopathy prompted us to consider the possibility of inherited metabolic disease. The baby had plasma ammonia of 
$1200 \mu \mathrm{mol} / \mathrm{L}$ (reference range 20-65 $\mu \mathrm{mol} / \mathrm{L}$ ). Plasma amino acid profile revealed elevated glycine of $2155 \mu \mathrm{mol} / \mathrm{L}$ (reference range 29$290 \mu \mathrm{mol} / \mathrm{L})$ and glutamine at $111 \mu \mathrm{mol} / \mathrm{L}$ (reference range 200-1200). Qualitative organic acid analysis in urine by gas chromatography mass spectrometry (GCMS) showed a large excretion of methyl citrate, propionyl glycine, 3hydroxypropionic acid and tiglyl glycine, thus confirming the diagnosis of PA. The cardiac involvement of PA was excluded by the normal echocardiogram and electrocardiogram. The neurological evaluation with the analysis of cerebrospinal fluid, electroencephalogram and brain imaging was withheld as the baby progressively deteriorated.

Our patient received supportive care, including parenteral nutrition with lipid emulsions and restriction of breastfeeding to limit the protein intake, sodium benzoate therapy as the ammonia scavenger and peritoneal dialysis to remove the toxic metabolites. Baby succumbed 5 days later despite all supportive care.

The PCCA and PCCB genes were analysed by polymerase chain reaction at CENTOGENE AG, Germany and sequencing of both DNA strands of the entire coding region and the highly conserved exon-intron splice junctions. The proband revealed a novel homozygous missense mutation, c. $860 \mathrm{C}>\mathrm{A}$ p.(Ala287Asp) in PCCB gene.

\section{Discussion}

PA (MIM \#606054) is a rare recessively inherited metabolic disorder of amino acid metabolism. The biochemical defect is within the mitochondrial enzyme PCC, which converts propionic acid to methyl malonic acid using biotin as a cofactor ${ }^{1,3}$. Accumulated organic acid metabolites interfere with other metabolic pathways such as urea cycle, electron transport chain and glycine synthase complex resulting in lactic acidosis, hyperammonaemia, and ketotic hyperglycinaemia ${ }^{4}$.

Disease onset is determined by several factors including residual enzyme activity, intake of propiogenic precursors and existence of catabolic status $^{5}$. Affected fetuses often follow an unremarkable perinatal period, though the risk of miscarriage is reported to be higher ${ }^{5}$. The classic, neonatal form due to complete enzyme deficiency is the most commonly encountered presentation ${ }^{1,5}$. It is characterized by progressive deterioration of a healthy neonate eventually evolve into encephalopathy ${ }^{5}$. The late-onset disease is described due to residual activity of PCC $^{5}$.

Long-term complications include neurological involvement, arrhythmias and dilated cardiomyopathy, dyslipidaemia ${ }^{3}$. Pancytopenias are well described to occur during acute decompensation secondary to the toxic metabolite accumulation in the bone marrow ${ }^{3,5}$. A localized or generalized exfoliative rash, hyperglycaemia due to insulin resistance and renal failure are recognized complications of $\mathrm{PA}^{6}$.

High anion gap MA, elevated lactate, hyperammonaemia, elevated urinary ketone bodies are the biochemical hallmark of $\mathrm{PA}^{4}$. However, during the initial period, the accumulation of propionate and other metabolites may not be sufficient to cause $\mathrm{MA}^{7}$. Hyperammonaemia can result in metabolic alkalosis, thereby delaying the diagnosis $^{7}$. Our patient had normal arterial $\mathrm{pH}$ on admission but later developed refractory MA.

Plasma amino acid profile along with urinary organic acids and genetic analysis result in the definitive diagnosis of PA. Since the duration of coma and high blood ammonia are well known to influence the future neurodevelopment, treatment should not be delayed due to unavailability of an exact diagnosis ${ }^{1}$. Initial stabilization, cessation of protein intake, measures to reverse catabolism and ammonia detoxification are the cornerstones of initial treatment ${ }^{1,5}$. Long term therapy comprises of L-carnitine to enhance propionyl group elimination, antibiotics (i.e. metronidazole) to reduce intestinal flora, low protein diet, addition of precursor free amino acids and calcium and vitamin D supplementation ${ }^{1,5}$. However, the mortality remains high despite all supportive care in the classic neonatal presentation and the long-term prognosis is guarded ${ }^{7}$.

The gene locus of PCCA is mapped to chromosome 13q32.3, whereas chromosome 3q13.3-q22 for the PCCB gene7. The sequencing of PCCA and PCCB genes in our patient detected a homozygous mutation at c. $860 \mathrm{C}>\mathrm{A}$ in the $\mathrm{PCCB}$ gene leading to p.(Ala287Asp) amino acid variation which lead to a missense mutation. The genotypic data were mapped to NCBI ClinVar and dbSNP 137 databases and identified to be a novel mutation

We conclude that it is worthwhile to consider organic acidaemia as an aetiology in neonatal encephalopathy. Neonatal sepsis mimics most of these conditions. The prerequisite of an expanded newborn screening for inherited metabolic diseases is emphasized with this case. We identified the above mentioned novel mutation in the PCCB gene and it is the first described PA genotype in Sri Lanka. 


\section{Acknowledgement}

We thank the Metabolic Disease Laboratory, Texas, United States of America for performing the GCMS and the Rare Disease Company, CENTOGENE AG, Germany for carrying out the genetic testing for our patient.

\section{References}

1. Baumgartner MR, Hörster F, Dionisi-Vici C, Haliloglu G, Karall D, Chapman KA, et al. Proposed guidelines for the diagnosis and management of methyl malonic and propionic acidaemia. Orphanet Journal of Rare Diseases 2014; 9:130. https://doi.org/10.1186/s13023-014-01308

PMid: 25205257 PMCid: PMC4180313

2. Hsia YE, Scully KJ, Rosenberg LE. Inherited propionyl-CoA carboxylase deficiency in "ketotic hyperglycinaemia". The Journal of Clinical Investigation 1971; 50(1):127-30.

https://doi.org/10.1172/JCI106466

PMid: 5101292 PMCid: PMC291900

3. Feliz B, Witt DR, Harris BT. Propionic acidaemia: a neuropathology case report and review of prior cases. Archives of Pathology \& Laboratory Medicine 2003; 127(8):e325-8.

4. Sindgikar SP, Rao S, Shenoy RD, Kamath $\mathrm{N}$. Biochemical basis of heterogenicity in acute presentations of propionic academia. Indian Journal of Clinical Biochemistry 2013; 28(1):95-7. https://doi.org/10.1007/s12291-012-02187

PMid: 24381430 PMCid: PMC3547454
5. Shchelochkov OA, Carrillo N, Venditti C. Propionic acidaemia. 2012 May 17 [Updated 2016 Oct 6]. In: Pagon RA, Adam MP, Ardinger HH, et al., editors. GeneReviews ${ }^{\circledR}$ [Internet]. Seattle (WA): University of Washington, Seattle; 19932019. Available from:

https://www.ncbi.nlm.nih.gov/books/NBK 92946/

6. Pena L, Franks J, Chapman KA, Ah Mew N, Chakrapani A, et al. Natural history of propionic acadaemia. Molecular Genetics and Metabolism 2012; 105(1):5-9.

https://doi.org/10.1016/j.ymgme.2011.09. 022

PMid: 21986446

7. Walter JH, Wraith JE, Cleary MA. Absence of acidosis in the initial presentation of propionic acidaemia. Archives of Disease in Childhood 1995; 72: F197-F199.

https://doi.org/10.1136/fn.72.3.F197

PMid: 7796239 PMCid: PMC2528453

8. Grünert $\mathrm{C}$, Müllerleile $\mathrm{S}$, De Silva $\mathrm{S}$, Barth $\mathrm{M}$, Walter $\mathrm{M}$, Walter $\mathrm{K}$, et al. Propionic acadaemia: clinical course and outcome in 55 paediatric and adolescent patients. Orphanet Journal of Rare Diseases 2013; 8: 6.

https://doi.org/10.1186/1750-1172-8-6

PMid: 23305374 PMCid: PMC3568723 